\title{
NUCLEAR SPECTROSCOPIC STUDIES OF THE 23.7 h ${ }^{248} \mathrm{Bk}{ }^{\dagger}$
}

\author{
H. C. GRIFFIN \\ Department of Chemistry, University of Michigan, Amn Arhor, Michigan 48109 \\ and \\ I. AHMAD, A. M. FRIEDMAN and L. E. GLENDENIN \\ Chemistry Division, Argonne National Laboratory, Argonne, Illinois 60439
}

Received 20 March 1978

\begin{abstract}
Main features of the decay of the $23.7 \mathrm{~h}{ }^{248} \mathrm{Bk}$ have been determined by spectroscopy with scintillation and semiconductor detectors. The results are as follows : half-life $23.7 \pm 0.2 \mathrm{~h}$; branching is $(30 \pm 5) \%$ to ${ }^{248} \mathrm{Cm}\left(\approx 23 \%\right.$ EC decay to $0^{+}$ground state and $\approx 7 \%$ to first $2^{+}$state) and $(70 \pm 5) \% \beta^{-}$decay to ${ }^{248} \mathrm{Cf}\left(5 \%\right.$ to $592 \mathrm{keV} K^{\approx}=2^{-}$state and $(65 \pm 5) \%$ to the ground-state band). The $\beta^{-}$decay energy, $Q_{\beta-}$, has been measured to be $860 \pm 20 \mathrm{keV}$, and the electron capture decay energy, $Q_{\mathrm{EC}}$, has been derived from closed cycle to be $705 \pm 25 \mathrm{keV}$. The deduced $\log f t$ values of $\beta^{-}$ and $\mathrm{EC}$ transitions restrict the spin of the ${ }^{248} \mathrm{Bk}$ ground state to 1 , with configuration assignment $\left\{\mathrm{n}[734] \frac{9}{2}^{-}: \mathrm{p}[633] \frac{7}{2}^{+}\right\}$. It has also been deduced that the long lived isomer lies $65 \pm 40 \mathrm{keV}$ above the $23.7 \mathrm{~h}{ }^{248} \mathrm{Bk}$ ground state.
\end{abstract}

RADIOACTIVITY ${ }^{248} \mathrm{Bk}$ [from $\left.{ }^{248} \mathrm{Cm}(\mathrm{d}, 2 \mathrm{n}),{ }^{247} \mathrm{Bk}(\mathrm{n}, ;)\right]$; measured $T_{1 ; 2}, E_{;}, I_{;,}$, ${ }^{248} \mathrm{Bk}$.

\section{Introduction}

Two isomers of ${ }^{248} \mathrm{Bk}$ are known. The short-lived ${ }^{248} \mathrm{Bk}$ isomer was first synthesized by Hulet ${ }^{1}$ ) who deduced a half-life of $23 \pm 5 \mathrm{~h}$ by milking the daughter ${ }^{248} \mathrm{Cf}$ from berkelium produced in a helium-ion bombardment of mixed curium isotopes. Chetham-Strode ${ }^{2}$ ) reported production of ${ }^{248} \mathrm{Bk}$ by the ${ }^{247} \mathrm{Bk}(\mathrm{n}, \gamma)$ reaction; his characterization included half-life $(16 \pm 3 \mathrm{~h}), Q_{\beta}-(650 \pm 50 \mathrm{keV})$, and branching ratios $\left(\beta^{-} / \mathrm{EC}=2.4,<6 \% \beta^{-}\right.$intensity to the $42 \mathrm{keV} 2^{+}$state of ${ }^{248} \mathrm{Cf}$ ). A long-lived ${ }^{248} \mathrm{Bk}$ isomer was identified ${ }^{3}$ ) by mass spectroscopy but its decay could not be detected. A lower limit of $800 \mathrm{y}$ was deduced for its $\alpha$-decay. This isomer is also produced ${ }^{4}$ ) in the $\alpha$-decay of ${ }^{252}$ Es.

Schmorak ${ }^{5}$ ) has pointed out inconsistencies between the characteristics inferred by Chetham-Strode ${ }^{2}$ ) and those obtained from systematics (energies and single-

+ Work performed under the auspices of the Dvision of Basic Energy Sciences of the Department of Energy. 
particle state assignments) in this region. The results of the present investigation remove these inconsistencies.

\section{Source preparation}

Most of the measurements were made with four sources of ${ }^{248} \mathrm{Bk}$ prepared by the ${ }^{247} \mathrm{Bk}(\mathrm{n}, \gamma)$ reaction. The target material consisted of a portion of the long-lived berkelium prepared by Milsted et al. ${ }^{3}$ ) containing $\approx 10^{11}$ atoms of ${ }^{247} \mathrm{Bk}$. After irradiation the berkelium fraction was isolated and purified by extraction chromatography. Final samples had strengths of a few hundred disintegrations per sec. These yields indicate that the cross section for the ${ }^{247} \mathrm{Bk}(\mathrm{n}, \gamma)$ reaction is of the order of $10^{3} \mathrm{~b}$.

One ${ }^{248} \mathrm{Bk}$ sample (used for obtaining $\mathrm{Ge}(\mathrm{Li})$ spectra) was produced by the irradiation of $\approx 2 \mathrm{mg}$ of ${ }^{248} \mathrm{Cm}$ with $20 \mathrm{MeV}$ deuterons in the Argonne $152 \mathrm{~cm}$ cyclotron. The beam current density was $30 \mu \mathrm{A} / \mathrm{cm}^{2}$ and the bombardment time was $16 \mathrm{~h}$. The $\mathrm{Cm}$ target was dissolved in $10 \mathrm{M} \mathrm{HNO}_{3}, 0.1 \mathrm{M} \mathrm{KBrO}_{3}$ solution and the Bk was extracted ${ }^{6}$ ) three successive times with equal volumes of $0.14 \mathrm{~F}$ di-(2-ethylhexyl) orthophosphoric acid in $\mathrm{n}$-heptane. The $\mathrm{Bk}$ was recovered from the organic phase by contact with a $10 \mathrm{M} \mathrm{HNO}_{3}, 0.1 \mathrm{M} \mathrm{H}_{2} \mathrm{O}_{2}$ solution. Fission products were removed by an extraction chromatographic procedure ${ }^{7}$ ). The chemically purified $\mathrm{Bk}$ was run through the Argonne electromagnetic isotope separator ${ }^{8}$ ) to prepare a massseparated ${ }^{248} \mathrm{Bk}$ sample. The sample contained $\approx 10^{5}$ disintegrations per minute of $23.7 \mathrm{~h}^{248} \mathrm{Bk}$.

\section{Experimental procedures and results}

The decay characteristics of ${ }^{248} \mathrm{Bk}$ were determined from a variety of measurements, some of which were intended only for qualitative characterizations (such as detecting coincidences without measuring absolute intensities). However, even the qualitative measurements indicated significant features of the decay which do not agree with the conclusions of Chetham-Strode ${ }^{2}$ ). In particular, we found a longer half-life, a $550.7 \mathrm{keV}$ transition in ${ }^{248} \mathrm{Cf}$, and substantial intensity of L-converted transitions in both ${ }^{248} \mathrm{Cm}$ and ${ }^{248} \mathrm{Cf}$. The half-life was determined both by $\beta^{-}$ counting and by following the decay of the $550.7 \mathrm{keV} \gamma$-ray. Assignment of the $\gamma$-ray as a transition in ${ }^{248} \mathrm{Cf}$ was based on $\beta^{-}-\gamma$ conincidences. Population of $\mathrm{L}$-converted transitions was detected by $\mathrm{K}_{\beta}-\mathrm{L} \mathrm{X}$-ray and $\beta$-L $\mathrm{X}$-ray coincidence experiments.

The individual measurements which bear most directly on the quantitative conclusions are described in the following subsections and are summarized in sect. 4.

\subsection{GAMMA-RAY SPECTROSCOPY}

The $\gamma$-ray spectrum of a mass-separated ${ }^{248} \mathrm{Bk}$ sample was measured with a $25 \mathrm{~cm}^{3}$ $\mathrm{Ge}(\mathrm{Li})$ spectrometer. Portions of the spectrum are shown in fig. 1 ; energies, intensities 


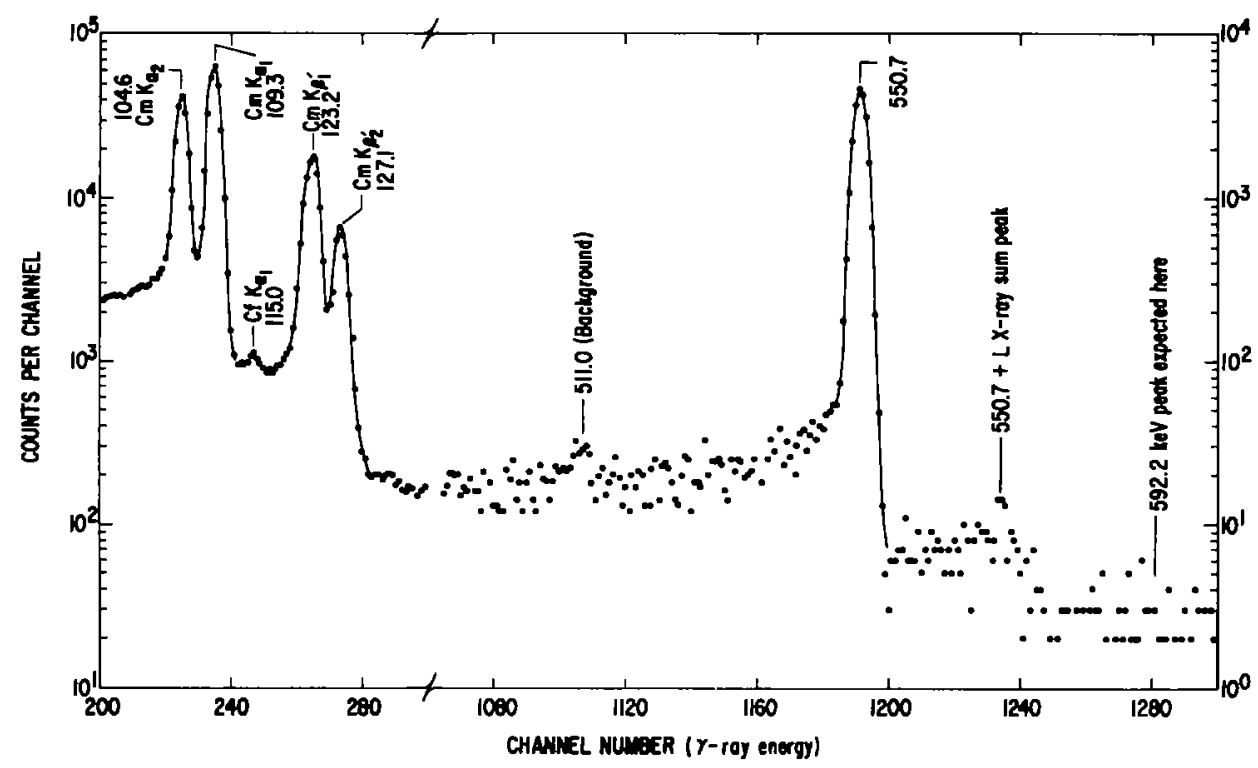

Fig. !. Gamma-ray spectrum of a mass-separated ${ }^{248} \mathrm{Bk}$ sample measured with a $25 \mathrm{~cm}^{3} \mathrm{Ge}(\mathrm{Li})$ spectrometer. The source was placed $\approx 4 \mathrm{~cm}$ away from the detector end cap and the counting time was $5.0 \mathrm{~h}$.

TABLE 1

K X-rays and $;$-rays associated with the decay of the $23.7 \mathrm{~h}{ }^{248} \mathrm{Bk}$

\begin{tabular}{|c|c|c|}
\hline Energy (keV) & Relative intensity *) & Transition \\
\hline $104.6+0.1$ & $65+3$ & $\mathrm{Cm} \mathrm{K}$ \\
\hline $109.3 \pm 0.1$ & 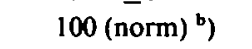 & $\mathrm{Cm} \mathrm{K}_{x_{1}}$ \\
\hline $115.0 \pm 0.3$ & $0.28 \pm 0.04$ & $\mathrm{Cf} \mathrm{K}_{\mathrm{a}}$ \\
\hline $123.2 \pm 0.2$ & $39.0 \pm 3.0$ & $\mathrm{Cm} \mathrm{K}{ }_{\beta_{i}^{\prime}}$ \\
\hline $127.1 \pm 0.2$ & $13.0 \pm 1.6$ & $\mathrm{Cm} \mathrm{K} \mathrm{K}_{B^{\prime}}$ \\
\hline $550.7 \pm 0.1$ & $51 \pm 3$ & $592.2 \rightarrow 41.5$ \\
\hline
\end{tabular}

a) The absolute intensity of the $550.7 \mathrm{keV} \gamma$-ray was measured to be $5.0 \pm 0.4 \%$ per $23.7 \mathrm{~h}{ }^{248} \mathrm{Bk}$ decay.

b) The total $\mathrm{Cm} \mathrm{K} \mathrm{X-ray} \mathrm{and} \mathrm{Cf} \mathrm{K} \mathrm{X-ray} \mathrm{intensities} \mathrm{are} 217$ and 0.6 , respectively.

and assignments are summarized in table 1 . In addition to $\mathrm{Cm} \mathrm{K} \mathrm{X-rays} \mathrm{which} \mathrm{arise}$ from K-capture, a Cf $\mathrm{K}_{\alpha_{1}} \mathrm{X}$-ray peak and a $550.7 \mathrm{keV} \gamma$-ray are present. The energy of the $\gamma$-ray was measured with respect to the $569.69 \mathrm{keV} \gamma$-ray of ${ }^{207} \mathrm{Bi}$; the source and the standard were counted simultaneously. We assume that since no other $\gamma$-transition in ${ }^{248} \mathrm{Cf}$ with energy greater than the $\mathrm{K}$-edge has been observed, all the Cf K X-ray intensity must originate from the shake-off during $\beta^{-}$decay and internal conversion of the $550.7 \mathrm{keV}$ transition. Using the $\mathbf{K}_{\text {total }} / \mathbf{K}_{\alpha_{1}}$ ratio ${ }^{9}$ ) of $2.15, \mathrm{~K}-$ fluorescence yield ${ }^{10}$ ) of 0.972 and a $K / \beta^{-}$shake-off yield ${ }^{11}$ ) of $2 \times 10^{-4}$, we have 
calculated the K-conversion coefficient of the $550.7 \mathrm{keV}$ transition as $0.009 \pm 0.002$. This is in good agreement with the theoretical ${ }^{12}$ ) value of 0.011 for an $\mathrm{E} 1$ transition. Theoretical values for a $550.7 \mathrm{keV} \mathrm{M} 1$ and $\mathrm{E} 2$ transition are 0.28 and 0.031 , respectively.

The data in table 1 indicate that the ratio between the $\mathrm{Cm} \mathrm{K} \mathrm{X}$-ray intensity and $550.7 \mathrm{keV}$ photon intensity is $4.25 \pm 0.28$. Similar measurements with scintillation detectors yielded a value of 4.0 with a statistical error of 0.1 . Consideration of possible systematic error leads to an average value of $4.15 \pm 0.20$. For an allowed or a firstforbidden non-unique EC transition with $Q_{\mathrm{EC}}=705 \mathrm{keV}$ we expect ${ }^{13}$ ) intensities of $0.74,0.18,0.02$ and 0.06 for $\mathrm{K}, \mathrm{L}_{\mathrm{l}}, \mathrm{L}_{\mathrm{II}}$ and $(\mathrm{M}+\mathrm{N}+\ldots)$ capture, respectively. Using the above numbers we obtain the ratio of the EC decay to the $550.7 \mathrm{keV}$ $\gamma$-emission as $5.79 \pm 0.28$.

The $\beta^{-}$disintegration rate of one ${ }^{248} \mathrm{Bk}$ sample was determined by two methods. First, the sample was counted in a $2 \pi$ geometry gas-flow counter at various discriminator settings. The counts corresponding to energies above $\approx 40 \mathrm{keV}$ were extrapolated to zero discriminator setting to give the total $\beta^{-}$disintegration rate. Second, the residual ${ }^{248} \mathrm{Cf}$ resulting from ${ }^{248} \mathrm{Bk}$ decay was assayed by $\alpha$-particle spectroscopy. Although the direct $\beta^{-}$measurements had negligible statistical errors, the $\alpha$-counts in the ${ }^{248} \mathrm{Cf}$ peaks were free from any systematic errors. The $\gamma$-emission rate of the sample was determined with a $\mathrm{NaI}(\mathrm{Tl})$ spectrometer of well-known detector characteristics. The best value of the $550.7 \mathrm{keV} \gamma / \beta^{-}$intensity ratio, obtained from several measurements, is $0.071 \pm 0.005$.

The decay of the $550.7 \mathrm{keV}$ photopeak in a spectrum measured with the $25 \mathrm{~cm}^{3}$ $\mathrm{Ge}(\mathrm{Li})$ spectrometer was followed for 6 days. A weighted least-squares analysis of the peak areas gave a half-life of $23.5 \pm 0.2 \mathrm{~h}$. A value of $23.99 \pm 0.03 \mathrm{~h}$ was obtained from $\beta^{-}$counting, but it is difficult to evaluate systematic errors in this measurement. We conclude the best value for the ${ }^{248} \mathrm{Bk}$ half-life is $23.7 \pm 0.2 \mathrm{~h}$.

\subsection{COINCIDENCE MEASUREMENTS}

The relative intensities of electron capture transitions to the $0^{+}$ground state and $2^{+}$first excited state of ${ }^{248} \mathrm{Cm}$ were determined from coincidences among $\mathrm{Cm} \mathrm{X}$-rays. The spectra displayed in fig. 2 were measured with two $7.6 \mathrm{~cm} \times 7.6 \mathrm{~cm} \mathrm{NaI(Tl)}$ detectors. Coincidence correlations were obtained with a two-parameter analyzer in which digital gates were set on one of the parameters. In principle the desired branching ratio can be obtained from either the $\mathrm{K}_{\beta}-\mathrm{L} \mathrm{X}$-ray coincidence intensity or the $\mathrm{L}$ X-ray versus $\mathrm{L}$ X-ray coincidence intensity. Although both coincidence spectra were analyzed, the latter is less sensitive to uncertainties in peak shapes.

The $\mathrm{L} X$-ray versus $\mathrm{L} X$-ray coincidences arise from two types of events - $\mathbf{L}$-capture to a level which deexcites predominantly by L-converted transitions and $\mathrm{K}$-capture (only $\mathrm{K}_{\alpha}$ emission is accompanied by $\mathrm{L}$-shell vacancies) to a similar level. In order to avoid dependence on absolute geometries and the efficiency of the coincidence 


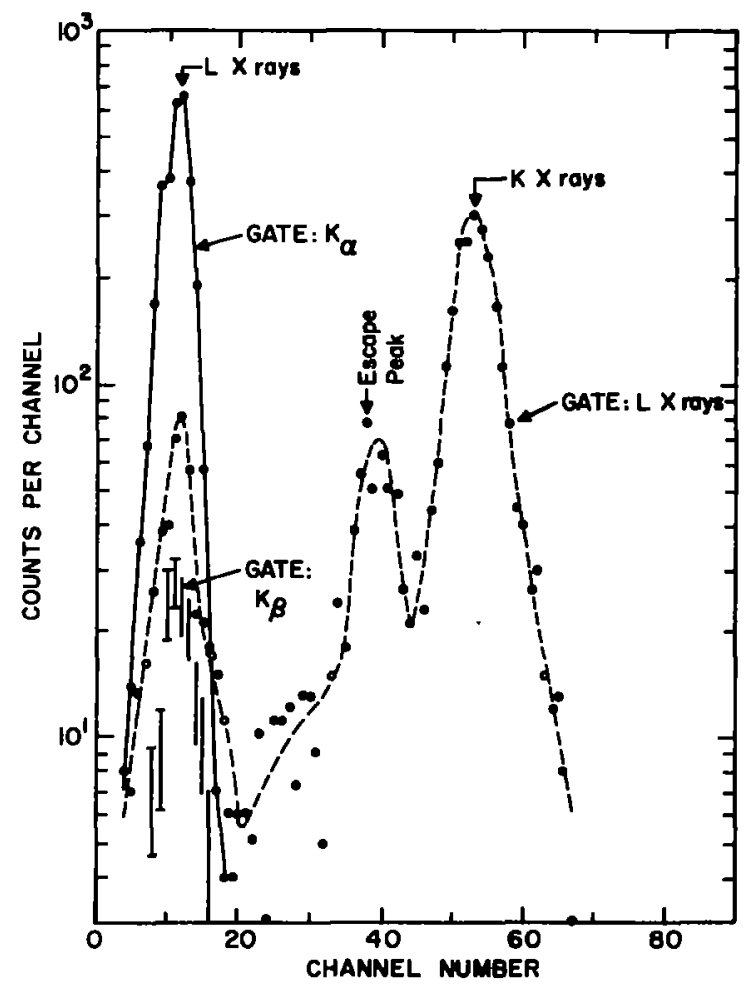

Fig. 2. The ${ }^{248} \mathrm{Bk} \gamma$-ray spectra measured with a $7.6 \mathrm{~cm} \times 7.6 \mathrm{~cm} \mathrm{NaI}(\mathrm{Tl})$ detector in coincidence with $\mathrm{Cm} \mathrm{K} \mathrm{K}_{\mathrm{x}}$ (denoted by $\bullet$ ), $\mathrm{Cm} \mathrm{K}_{\mathrm{p}}$ (error bars) and $(\mathrm{Cm}+\mathrm{Cf}) \mathrm{L} \mathrm{X}$-rays $(0)$. The first two spectra have 0 to 1 count per channel beyond $\mathrm{L} X$-ray region.

circuit, the L X-ray-L X-ray coincidence spectrum was compared with the L X-ray spectrum gated by the $K_{\alpha}$ peak. The latter arises primarily from atomic processes following K-capture. In the analysis we have used a value of $0.54 \pm 0.01$ for the average L-fluorescence yield and assumed that it is relatively insensitive to the distribution of primary vacancies among $\mathrm{L}$-subshells ${ }^{14}$ ). Experimental values of fluorescence yields in $\mathrm{Cm}$ are $0.28,0.55$ and 0.63 for the $\mathrm{L}_{1}, \mathrm{~L}_{\mathrm{II}}$ and $\mathrm{L}_{\mathrm{III}}$ subshells, respectively. Theoretical values of conversion coefficients and capture intensities from various shells were also used in these analyses. The analysis of the $\mathrm{L} \mathrm{X-ray-L} \mathrm{X-ray} \mathrm{coincidence} \mathrm{data} \mathrm{indicates}$ that $(18 \pm 2) \%$ of EC decays populate the $2^{+}$level in ${ }^{248} \mathrm{Cm}$. Analysis of the $\mathrm{K}_{\beta}-\mathrm{L}$ $\mathrm{X}$-ray coincidence spectrum gives a value of $(35 \pm 10) \%$ for this intensity. From the weighted average we obtain a value of $(22 \pm 5) \%$ for the EC intensity at $2^{+}$state.

The data bearing on the $\beta^{-}$branching to the $0^{+}$and $2^{+}$levels in ${ }^{248} \mathrm{Cm}$ are rather qualitative. A comparison of the ${ }^{248} \mathrm{Bk} \mathrm{L} \mathrm{X-ray} \mathrm{singles} \mathrm{spectrum} \mathrm{(fig.} \mathrm{3)} \mathrm{with} \mathrm{Cm} \mathrm{L}$ $\mathrm{X}$-ray spectrum in coincidence with $\mathrm{K} \mathrm{X}$-ray and Cf $\mathrm{L} \mathrm{X}$-ray spectrum gated by $\beta^{-}$particles indicates that the contributions from the two elements are almost equal. The end point of the $\beta^{-}$spectrum (fig. 4) measured in coincidence with L X-rays 


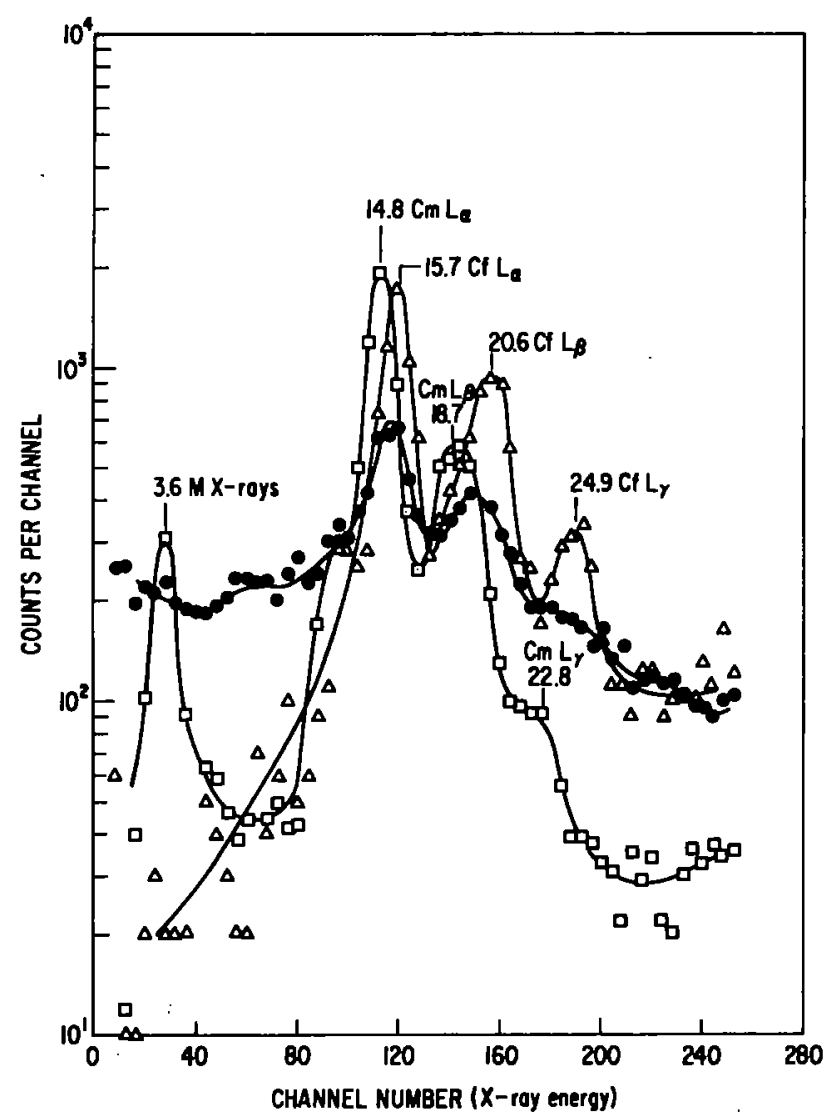

Fig. 3. The ${ }^{248}$ Bk L X-ray spectra measured with a proportional counter. Spectrum denoted by represents singles spectrum and the spectra denoted by $\square$ and $\Delta$ were obtained in coincidence with $\mathrm{Cm} \mathrm{K} \mathrm{X-rays} \mathrm{and} \boldsymbol{\beta}^{-}$particles, respectively.

suggests that the L-converted transitions in ${ }^{248} \mathrm{Cf}$ are fed predominantly by high energy $\beta^{-}$transitions, from which we infer that the Cf L X-rays originate from the $2^{+}$ level in ${ }^{248} \mathrm{Cf}$. From a quantitative analysis of coincident $\beta^{-}$spectra we find that the total intensity of the $\beta^{-}$group feeding the $2^{+}$level is at least three times that attributed to the $550.7 \mathrm{keV} \gamma$-ray intensity but less than one-half the total $\beta^{-}$intensity.

\subsection{THE $\beta^{-}$SPECTROSCOPY}

The $\beta^{-}$spectra, more quantitative than those given in fig. 4 , were obtained to determine $Q_{\beta}$ - for ${ }^{248} \mathrm{Bk}$ decay and to confirm the assignment of the $550.7 \mathrm{keV} \gamma$-ray. The relevant spectra are displayed in fig. 5. The Fermi-Kurie plot of the ${ }^{248} \mathrm{Bk}$ singles spectrum measured with a $\mathrm{Si}(\mathrm{Li})$ detector (curve $\mathrm{A}$ ) shows significant curvature which we assume to arise from edge effects in and scattering from the detector. The energy 


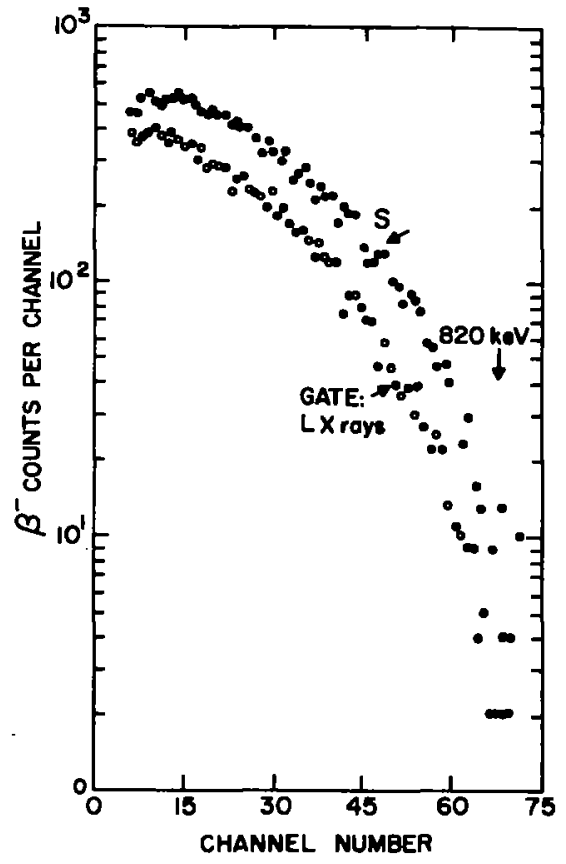

Fig. 4. The ${ }^{248} \mathrm{Bk} \beta^{-}$spectrum measured with a Pilot $\mathrm{B}$ scintillator in coincidence with $\mathrm{Cm}$ and $\mathrm{Cf}$ $\mathrm{L} X$-rays. The $\beta^{-}$singles spectrum (S) is shown for comparison.

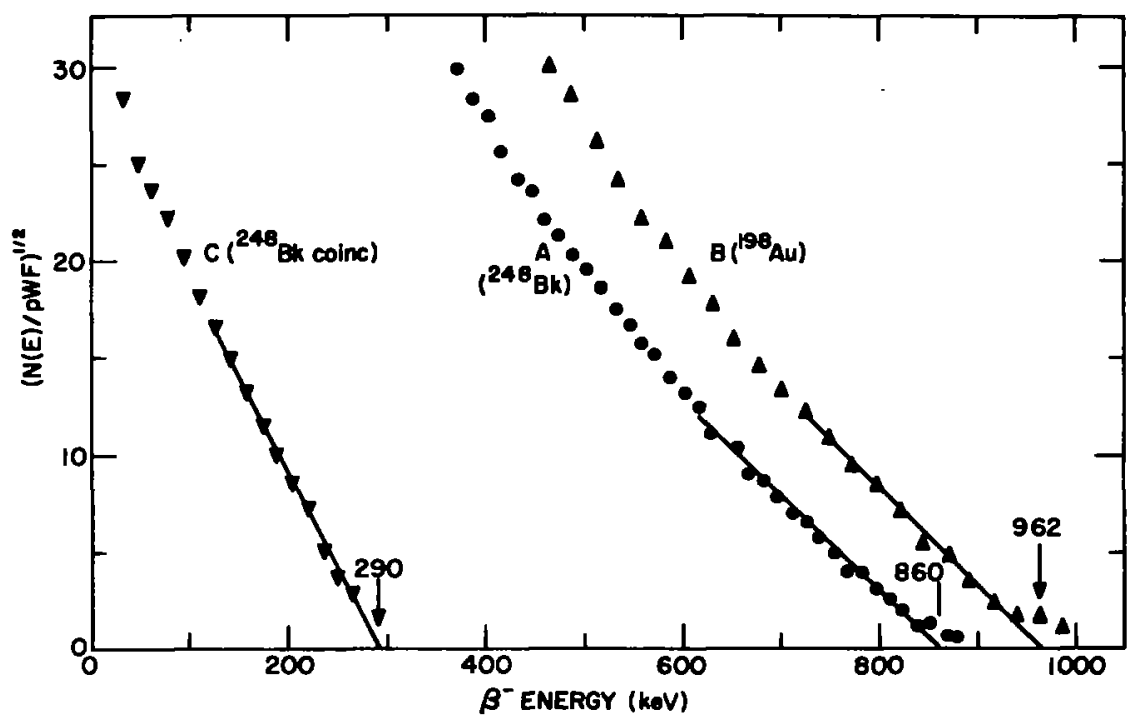

Fig. 5. Fermi-Kurie plot of a ${ }^{248} \mathrm{Bk} \beta^{-}$singles spectrum measured with a $\mathrm{Si}(\mathrm{Li})$ detector. $\mathrm{A}^{198} \mathrm{Au}$ spectrum measured with the same detector is shown for comparison. The $\beta^{-}$spectrum $C$ was obtained with a liquid scintillator in coincidence with the $550.7 \mathrm{keV} \gamma$-ray. 
calibration was obtained with ${ }^{207} \mathrm{Bi}$ conversion electron lines. $\mathrm{A}^{198} \mathrm{Au}$ spectrum was used to establish the linear range of the Fermi-Kurie plot. Since the energy range used for the extrapolation is large compared with the $41.5 \mathrm{keV}$ energy difference between the $0^{+}$and $2^{+}$states of ${ }^{248} \mathrm{Cf}$, the observed end point can be interpreted as a weighted average of the true end points of the transitions to these two states. These data yield a value of $870 \pm 20 \mathrm{keV}$ for $Q_{\beta^{-}}$.

For the measurement of $\beta^{-}$transitions leading to the $550.7 \mathrm{keV} \gamma$-ray, the ${ }^{248} \mathrm{Bk}$ sample was dissolved in a liquid scintillator and $\gamma$-rays were detected with a $\mathrm{NaI}(\mathrm{Tl})$ detector. The energy calibration and the resolution response function of the liquid scintillator were measured with several conversion-electron sources. The Fermi-Kurie plot of the resolution-corrected spectrum is shown as curve $\mathrm{C}$ of fig. 5. The observed end-point energy of $290 \mathrm{keV}$ is interpreted as a sum of the true $\beta^{-}$end-point energy and the energies of the internal conversion electrons and X-rays from the $2^{+} \rightarrow 0^{+}$ transition in ${ }^{248} \mathrm{Cf}$. The analysis of curve $\mathrm{C}$ gives a true end-point energy of $257 \mathrm{keV}$ and the ground-state $\beta^{-}$decay energy of $849 \mathrm{keV}(257+592)$. The above two measurements of $Q_{\beta}$ - agree within the uncertainties assigned to them and yield the average value of $860 \pm 20 \mathrm{keV}$. The measured end-point energy of the $\beta^{-}$spectrum in coincidence with $\mathrm{Cf} \mathrm{L} \mathrm{X}$-rays and the fact that the $550.7 \mathrm{keV} \gamma$-ray is in coincidence with Cf L X-rays strongly suggest that the $550.7 \mathrm{keV} \gamma$-transition terminates at the $41.5 \mathrm{keV}$ $2^{+}$state of ${ }^{248} \mathrm{Cf}$.

\section{Discussion}

The decay scheme of the $23.7 \mathrm{~h}{ }^{248} \mathrm{Bk}$ deduced from the present investigation is shown in fig. 6. The characteristics of the ground-state bands of ${ }^{248} \mathrm{Cm}$ and ${ }^{248} \mathrm{Cf}$ are known from $\alpha$-decay studies ${ }^{5.15}$ ) of ${ }^{252} \mathrm{Cf}$ and ${ }^{252} \mathrm{Fm}$. A comparison of EC and $\beta^{-}$ intensities to the $550.7 \mathrm{keV} \gamma$-intensity leads to absolute intensities of $(5.0 \pm 0.4) \%$, $(70 \pm 5) \%$ and $(30 \pm 5) \%$ for the $550.7 \mathrm{keV} \gamma$, total $\beta^{-}$and total EC transition,

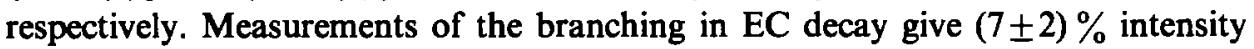
to the $2^{+}$state and $(23 \pm 4) \%$ to the ${ }^{248} \mathrm{Cm}$ ground state. A similar analysis gave $\beta^{-}$ intensity of $(45 \pm 10) \%$ and $(20 \pm 10) \%$ to the $0^{+}$and $2^{+}$members of ground-state band; the total intensity to the ground-state band is $(65 \pm 5) \%$.

The $\beta^{-}$spectral measurements and $\gamma$ versus $\mathrm{L} X$-ray coincidences indicate that the $550.7 \mathrm{keV}$ El transition deexcites a $592.2 \mathrm{keV}$ level to the $41.5 \mathrm{keV}$ level. The absence of parallel transitions ( $<\frac{1}{300}$ of the $550.7 \mathrm{keV} \gamma$-intensity) implies that the $592.2 \mathrm{keV}$ state has $I^{\pi}=2^{-}$. The comparative half-lives ${ }^{16}$ ) for EC and $\beta^{-}$transitions constrain the ground state of ${ }^{248} \mathrm{Bk}$ to $I=1$. The configuration for ${ }^{248} \mathrm{Bk}$ ground state can be deduced from the known single-particle orbitals in the neighboring odd-mass nuclei. The ground state of ${ }^{247} \mathrm{Cm}$ is known ${ }^{17}$ ) to be the $\frac{{ }^{2}}{2}[734]$ neutron orbital and that of ${ }^{247} \mathrm{Bk}$ is the $\frac{3}{2}^{-}$[521] proton state with the $\frac{7^{2}}{2}$ [633] orbital lying only $41 \mathrm{keV}$ away ${ }^{18}$ ). From the coupling of the above neutron and proton orbitals only one $I=1$ state is formed. We, therefore, assign the ${ }^{248} \mathrm{Bk}$ ground state to the $\left\{\mathrm{n}[734]_{\frac{2}{2}}^{-} ; \mathrm{p}[633]^{\frac{7}{2}}{ }^{+}\right\}$configuration. 

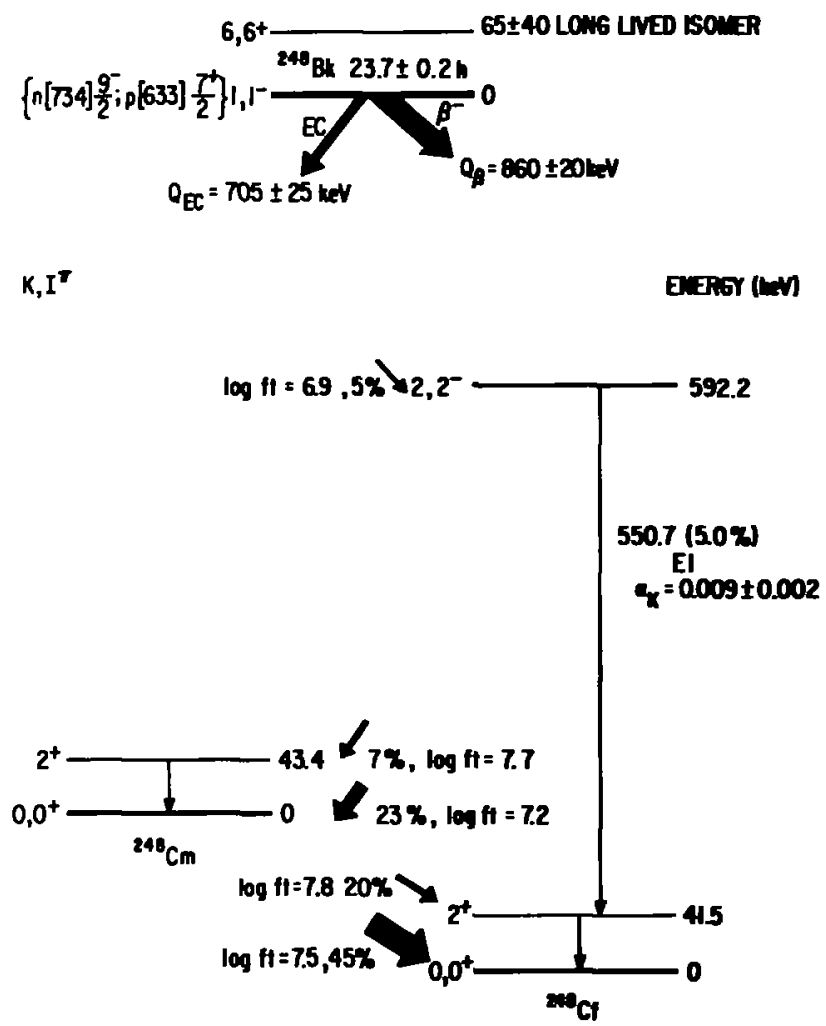

Fig. 6. Decay scheme of the $23.7 \mathrm{~h}{ }^{248} \mathrm{Bk}$ deduced from the present work.

Because of its low energy we interpret the $592.2 \mathrm{keV}$ state as a $K^{\pi}=2^{-}$octupole vibrational state. It should be pointed out that as such it would be the lowest $2^{-}$ octupole vibration known in the actinide region. This state was also observed in the ${ }^{249} \mathrm{Cf}(\mathrm{d}, \mathrm{t})$ reaction $\left.{ }^{19}\right)$ and it was given the same assignment. It was shown that this $K^{\pi}=2^{-}$band contains a large contribution from the $\left\{\mathrm{n}[734] \frac{9}{2}^{-} ; \mathrm{n}[622] \frac{5}{2}^{+}\right\}$ configuration. With this assignment the $\beta^{-}$transition to the $592.2 \mathrm{keV}$ state is equivalent to a transition between $\mathrm{p}[633] \frac{7}{2}^{+}$and $\mathrm{n}[622] \frac{5}{2}^{+}$orbitals in the neighboring odd-mass nuclei. The $\log f t$ value of EC transition involving these two states in ${ }^{249} \mathrm{Es}$ decay ${ }^{9}$ ) is determined to be 7.3 , which is close to the value of 6.8 observed in ${ }^{248} \mathrm{Bk}$ $\beta^{-}$decay. The small difference between the two values could be accounted for in terms of pair occupation probabilities of orbitals involved in the transitions.

The $\beta^{-}$decay energy of $860 \pm 20 \mathrm{keV}$ combined with the ${ }^{248} \mathrm{Cm}^{248} \mathrm{Cf}$ mass difference of $154 \pm 10 \mathrm{keV}$ yields a value of $Q_{\mathrm{EC}}$ as $705 \pm 25 \mathrm{keV}$ for ${ }^{248} \mathrm{Bk}$ EC decay. The Cm-Cf mass difference was derived from $\left.E_{a_{0}}\left({ }^{248} \mathrm{Cf}\right)=6262 \pm 5 \mathrm{keV}\left[\mathrm{ref} .{ }^{15}\right)\right]$, $Q_{a}\left({ }^{248} \mathrm{Cm}\right)=5161 \pm 5 \mathrm{keV}\left[\right.$ ref. $\left.\left.{ }^{5}\right)\right]$ and the ${ }^{244} \mathrm{Pu}-{ }^{244} \mathrm{Cm}$ mass difference of $1358 \pm 7$ $\mathrm{keV}\left[\right.$ ref. $\left.\left.{ }^{5}\right)\right]$. A similar analysis based on $Q_{\alpha}\left({ }^{252} \mathrm{Es}\right.$ to long-lived $\left.{ }^{248} \mathrm{Bk}\right)=6738 \pm 3$ 
$\mathrm{keV}\left[\right.$ ref. $\left.\left.\left.{ }^{4}\right)\right], Q_{\mathrm{EC}}\left({ }^{252} \mathrm{ES}\right)=1290 \pm 30 \mathrm{keV}\left[\mathrm{ref} .{ }^{4}\right)\right]$ and $Q_{\alpha}\left({ }^{252} \mathrm{Cf}\right)=6217 \pm 1 \mathrm{keV}$ [ref. $\left.{ }^{5}\right)$ ] indicates that $Q_{\mathrm{EC}}$ for the long-lived ${ }^{248} \mathrm{Bk}$ is $770 \pm 30 \mathrm{keV}$. Therefore the long-lived ${ }^{248} \mathrm{Bk}$ isomer lies $65 \pm 40 \mathrm{keV}$ above the $23.7 \mathrm{~h}{ }^{248} \mathrm{Bk}$ ground state. This energy difference is comparable to the error but it is much smaller than the difference implied by the value of $Q_{\beta}$ - reported by Chetham-Strode ${ }^{2}$ ). Other evidence indicates that the excitation energy of the long-lived isomer is unlikely to be as much as $100 \mathrm{keV}$. Milsted et al. ${ }^{3}$ ) obtained a lower limit of $10^{11} \mathrm{~s}$ for the partial half-life of the long-lived ${ }^{248} \mathrm{Bk}$ isomer for the production of ${ }^{248} \mathrm{Cf}$. Fields et al. ${ }^{4}$ ) obtained $I, K^{\pi}=6,6^{+}$for the long-lived isomer. Therefore ${ }^{248} \mathrm{Cf}$ production could arise either by direct $\beta^{-}$ decay of long-lived isomer or by a E5 isomeric transition to the $23.7 \mathrm{~h}^{248} \mathrm{Bk}$ followed by $\beta^{-}$decay to ${ }^{248} \mathrm{Cf}$. The half-life of a $100 \mathrm{keV}$ E5 transition is found to be substantially less than $10^{11} \mathrm{~s}$ on the basis of single-particle estimate ${ }^{13}$ ). This half-life argument suggests that the energy difference between the ground states of the two isomers is less than $100 \mathrm{keV}$.

The authors thank J. Lerner for the Isotope Separator preparation of the ${ }^{248} \mathrm{Bk}$ sample and H. Diamond, K. F. Flynn and R. K. Sjoblom for their help in chemical purifications and activity determination.

\section{References}

1) E. K. Hulet, Phys. Rev. 102 (1956) 182

2) A. Chetham-Strode. Jr., Lawrence Radiation Lab. Report UCRL-3322, Ph.D. thesis (1956)

3) J. Milsted. A. M. Friedman and C. M. Stevens, Nucl. Phys. 71 (1965) 299

4) P. R. Fields, I. Ahmad, R. F. Barnes, R. K. Sjoblom and Wm. C. McHarris, Nucl. Phys. A208 (1973) 269

5) M. R. Schmorak. Nucl. Data Sheets 17 , no. 3 (1976) 391

6) D. F. Peppard. S. W. Moline and G. W. Mason, J. Inorg. Nucl. Chem. 4 (1957) 344

7) I. Ahmad, R. F. Barnes, R. K. Sjoblom and P. R. Fields, J. Inorg. Nucl. Chem. 34 (1972) 3335

8) J. Lerner, Nucl. Instr. 102 (1972) 373

9) I. Ahmad. R. K. Sjoblom and P. R. Fields, Phys. Rev. C14 (1976) 218

10) I. Ahmad and R. K. Sjoblom, Proc. ERDA Symp. on X-and gamma-ray sources and applications, CONF-760539. Ann Arbor, Michigan, 19-21 May 1976, p. 249

11) T. A. Carlson, C. W. Nestor, Jr., T. C. Tucker and F. B. Malik, Phys. Rev. 169 (1968) 27

12) R. S. Hager and E. C. Seltzer, Nucl. Data A4 (1968) 1

13) C. M. Lederer, J. M. Hollander and I. Perlman, Table of isotopes, 6th ed. (Wiley, NY, 1967)

14) W. Bambynek, B. Crasemann, R. W. Fink, H.-U. Freund, H. Mark, C. D. Swift, R. E. Price and P. Venugopala Rao, Rev. Mod. Phys. 44 (1972) 716

15) I. Ahmad, unpublished results.

16) N. B. Gove and M. J. Martin, Nucl. Data Tables A10 (1971) 206

17) P. R. Fields, I. Ahmad, A. M. Friedman, J. Lerner and D. N. Metta, Nucl. Phys. A160 (1971) 460

18) I. Ahmad, A. M. Friedman, R. R. Chasman and S. W. Yates. Phys. Rev. Lett. 39 (1977) 12

19) S. W. Yates, R. R. Chasman, A. M. Friedman, I. Ahmad and K. Katori, Phys. Rev. C12 (1975) 442 